\title{
Co-Cu alloyed Nanoparticles by reactive milling.
}

\author{
J. F. Angeles-Islas, D. Ramirez-Rosales, R. Zamorano-Ulloa, H. A. Calderon. \\ ESFM-IPN, Zacatenco D.F., Mexico.
}

The synthesis of metallic nanoparticles of $\mathrm{Cu}, \mathrm{Co}$ and $\mathrm{Cu}-\mathrm{Co}$ by means of a mechanochemical process is reported. High energy mills are used. The reaction between powders and activated by ball milling involves metallic chlorides and $\mathrm{Na}$ in a protective $\mathrm{NaCl}$ environment. Such an environment hinders metallic agglomeration beyond a few nanometers producing a fine dispersion of nanoparticles. The present work includes synthesis of nanoparticles of pure Co (fcc or hcp) and $\mathrm{Cu}$. Additionally, nanoparticles of $\mathrm{Cu}-\mathrm{Co}$ in solid solution are also obtained in different compositions $\left(\mathrm{Cu}_{100-\mathrm{X}} \mathrm{Co}_{\mathrm{X}}\right.$ at.\%, with $\mathrm{X}=5$ and 20$)$ as a function of milling energy and volume fraction in $\mathrm{NaCl}$. They are produced by mixing the appropriate amount of metallic $\mathrm{Cu}$ and $\mathrm{Co}$ chlorides. The as milled powders are characterized by X-Ray diffraction, semiquantitative chemical analysis using energy dispersive spectrometry (EDS), transmission electron microscopy (TEM) in high resolution mode, and measurement of magnetic properties by EPR (electron paramagnetic resonance) and VSM (vibrating sample magnetometer).

Figure 1 shows the $\mathrm{X}$ ray diffraction patterns of some samples as a function of chemical composition. The amount of $\mathrm{Co}$ and $\mathrm{Cu}$ is given in atom percentage and represents the nominal values from the corresponding chlorides that have been milled for 10-40 h. Pure Co and $\mathrm{Cu}$ nanoparticles correspond to the expected lattice parameters, although in the case of Co, traces of Cohcp are also seen. As for the Cu-Co nanoparticles, the XRD patterns show that a solid solution is obtained. Similar results are obtained from the measurement of magnetic properties. Fig. 2 shows Low Field Signal (LFS) measurements taken in a conventional ESR spectrometer as a function of composition. The spectra show a degraded absorption hysteresis with respect to Co. The differences are attributed to the corresponding loss of magnetic order of $\mathrm{Co}$ as it is incorporated into the $\mathrm{Cu}$ lattice showing a strong magnetostatic field (usual in $\mathrm{Co}$ ) without the strong ferromagnetic coupling i.e., the formation of a solid solution. Figure 3 a shows a TEM image corresponding to a mixture of 80 at. $\% \mathrm{Cu}$ and 20 at.\% after $20 \mathrm{~h}$ of reactive milling. The volume fraction of nanoparticles on the foil has been increased by cleansing the $\mathrm{NaCl}$ in methanol. However it is difficult to clean completely the mixture and some $\mathrm{NaCl}$ still joins the metallic particles that give the appearance of many overlapped crystalline domains, as seen in Fig. 3. Nevertheless several particles can be seen away from the rest of the agglomerate, especially for sufficiently thin sections of the sample. Figs. $3 \mathrm{~b}-\mathrm{d}$ show selected particle images with the corresponding lattices. Fig. 3e shows an intensity profile that can be used to asses the shape of the particle. An spheroid particle would give increasing intensity values when moving from the edge to the center. The profile in Fig. 3e corresponding to the section indicated in Fig. 3c, shows precisely such a trend. Thus particle shape and average size can be deduced from this typ of images. Size and size distribution vary as a function of milling time and nominal composition. A direct measurement of chemical composition of the particles by TEM techniques is in progress.

References

[1] Financial support of IPN (COFAA, SIP) and CONACYT (research grant 58133) are gratefully acknowledged. 


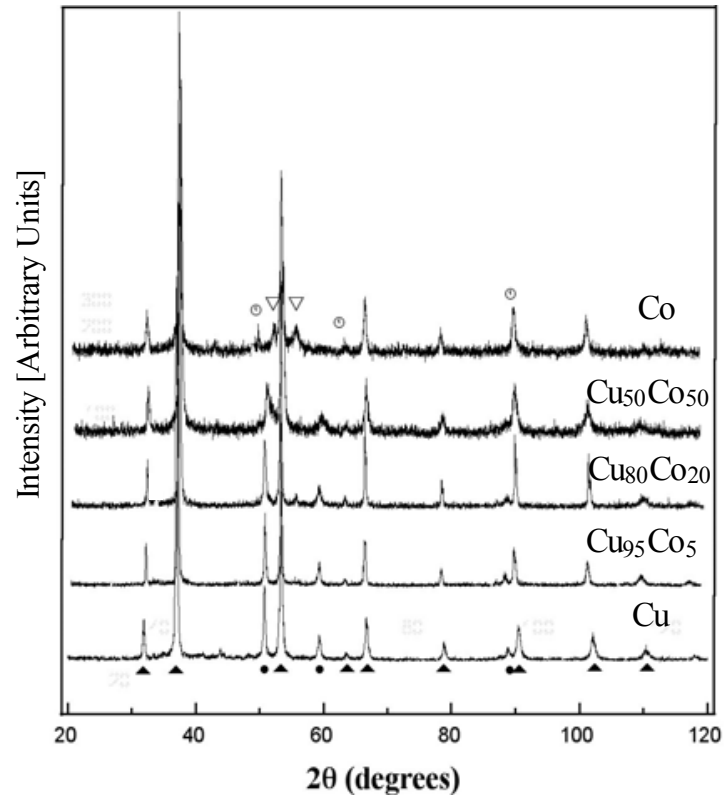

Fig. 1. X-ray diffraction patterns after milling $10 \mathrm{~h}$. The nominal particle composition is indicated.

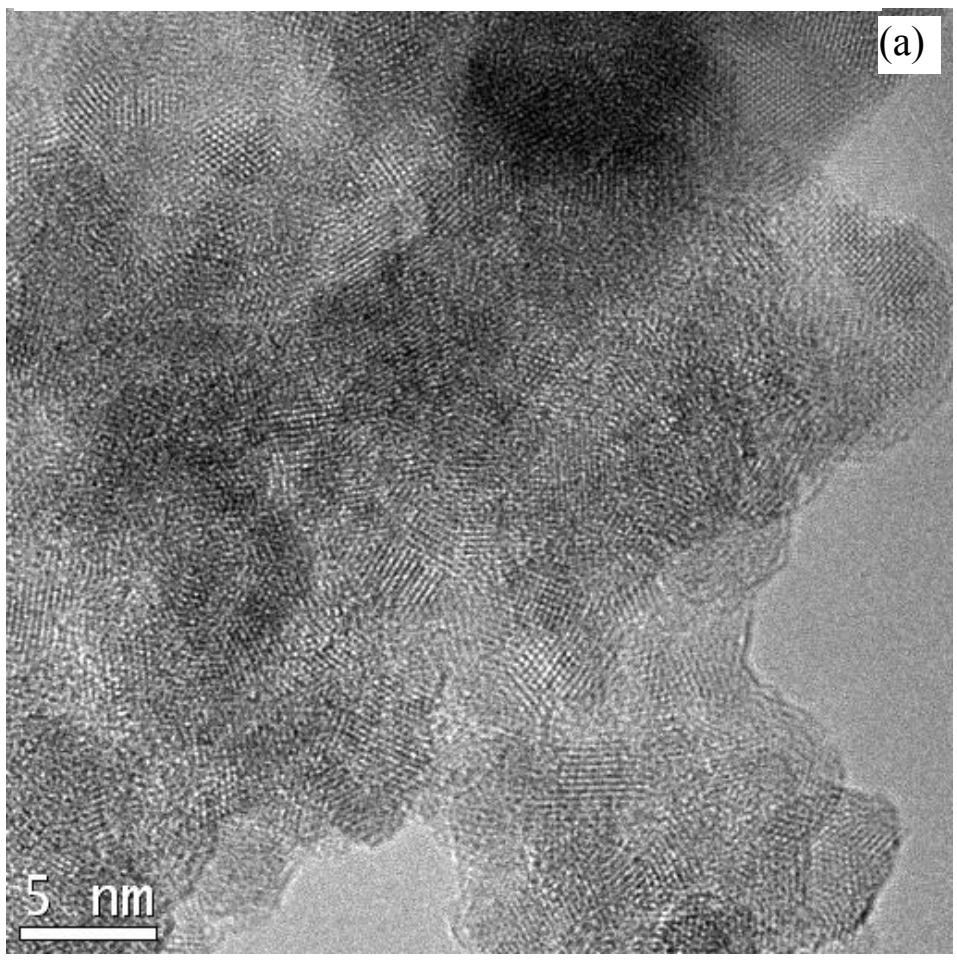

Fig. 3. (a) High resolution image of nanoparticles in the mixture containing $80 \% \mathrm{Cu}$ and $20 \% \mathrm{Co}$ (at.\%). (b-d) Selected images showing nanoparticles with sizes varying between 2 and $4 \mathrm{~nm}$ in diameter. (e) Intensity profile of column row indicated in (c) by means of an arrow. (a)

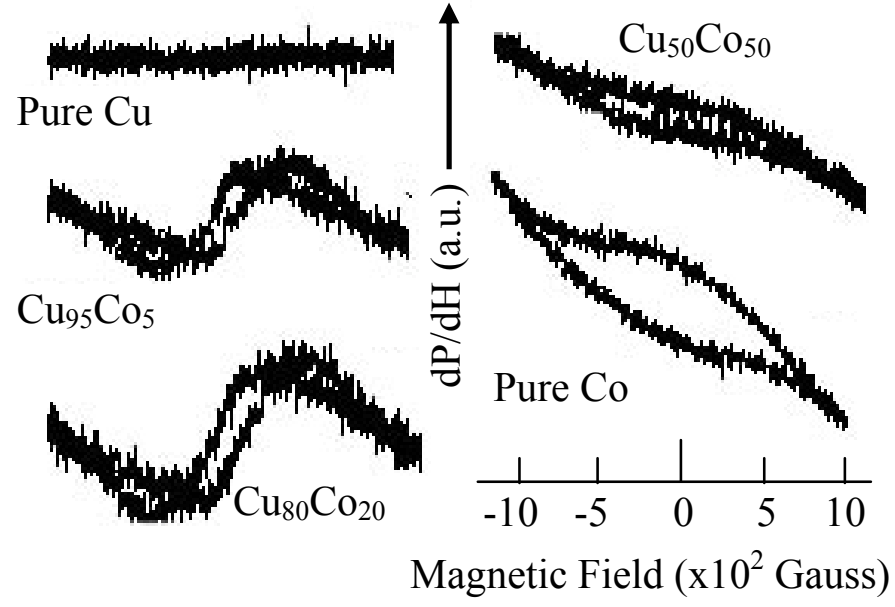

Figure 2. Magnetic properties (low field signal) of as milled powders with nanoparticles of different compositions.

(b)

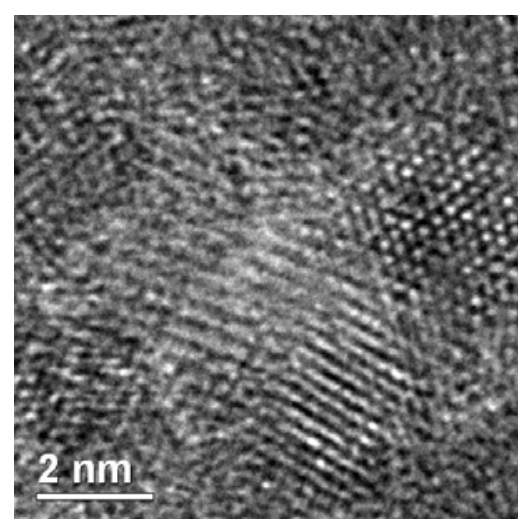

(c)

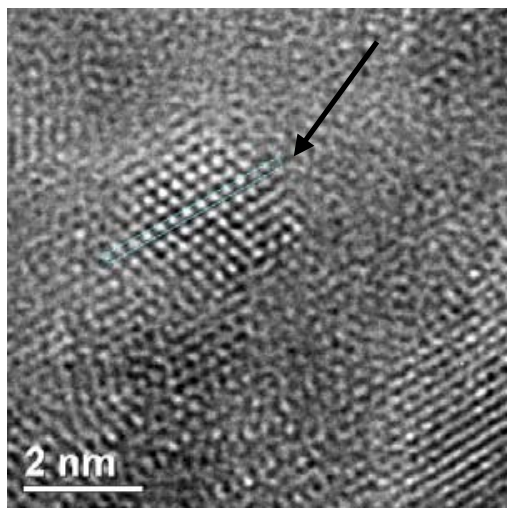

(d)
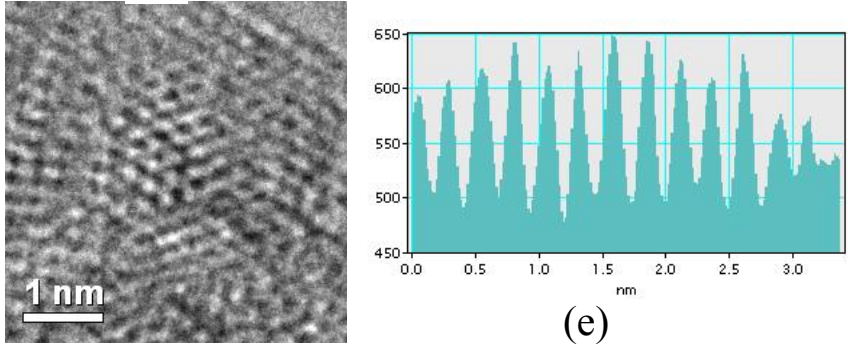

(e) 